\section{Smith ScholarWorks}

$12-1-2012$

\section{Resistance is Futile: The Bacteriocin Model for Addressing the Antibiotic Resistance Challenge}

\author{
Margaret A. Riley \\ University of Massachusetts Amherst \\ Sandra M. Robinson \\ University of Massachusetts Amherst \\ Christopher M. Roy \\ University of Massachusetts Amherst \\ Morgan Dennis \\ University of Massachusetts Amherst \\ Vivian Liu \\ University of Massachusetts Amherst
}

See next page for additional authors

Follow this and additional works at: https://scholarworks.smith.edu/bio_facpubs

Part of the Biology Commons

\section{Recommended Citation}

Riley, Margaret A.; Robinson, Sandra M.; Roy, Christopher M.; Dennis, Morgan; Liu, Vivian; and Dorit, Robert, "Resistance is Futile: The Bacteriocin Model for Addressing the Antibiotic Resistance Challenge" (2012). Biological Sciences: Faculty Publications, Smith College, Northampton, MA.

https://scholarworks.smith.edu/bio_facpubs/227 
Authors

Margaret A. Riley, Sandra M. Robinson, Christopher M. Roy, Morgan Dennis, Vivian Liu, and Robert Dorit 


\title{
Resistance is futile: the bacteriocin model for addressing the antibiotic resistance challenge
}

\author{
Margaret A. Riley"1, Sandra M. Robinson", Christopher M. Roy", Morgan Dennis", Vivian Liu* and Robert L. Dorit† \\ "Department of Biology, University of Massachusetts Amherst, 611 N. Pleasant Street Amherst, MA 01003, U.S.A., and †Department of Biological Sciences, \\ Smith College, Northampton, MA 01063, U.S.A.
}

\begin{abstract}
Pathogenic bacteria resistant to many or all antibiotics already exist. With the decline in microbiological research at pharmaceutical companies, the high rate at which resistance has evolved and spread has demanded a novel approach to addressing this critical human health issue. In the present paper, we propose a new paradigm in antibiotic discovery and development, one that applies ecological and evolutionary theory to design antimicrobial drugs that are more difficult and/or more costly to resist. In essence, we propose to simply adopt the strategies invented and applied by bacteria for hundreds of millions of years. Our research focuses on bacteriocins, powerful biological weapons, and their use as alternative therapeutics in human health.
\end{abstract}

\section{The challenges of antibiotic resistance}

The development and spread of bacterial antibiotic resistance has emerged as a major public health concern [1-4]. Pathogenic microbes, once easily controlled by antimicrobial drugs, now frequently fail to respond to many antibiotics. We are witnessing the emergence of multiply resistant pathogen strains in a broad range of species, including Staphylococcus aureus, Mycobacterium tuberculosis, Psendomonas aeruginosa, Salmonella enterica and Enterococcus faecium $[5,6]$. Multiply-resistant bacterial infections significantly increase the length of hospitalization, complicate the treatment of other conditions and frequently require the use of more toxic alternative treatments. More ominous is the marked increase in mortality from both Gram-negative and Grampositive infections associated with 'inappropriate antibiotic treatments', where resistant pathogens fail to respond to the course of treatment (http://www.who.int/mediacentre/ factsheets/fs194/en/). Increased antibiotic resistance also has important economic consequences. For example, in the U.S.A. alone, antibiotic-resistant infections are estimated to be responsible for US $\$ 20$ billion in excess health care costs in addition to US $\$ 35$ billion in societal costs [8].

Public and private approaches to deal with the emergence of bacterial resistance fall into two distinct categories. The first of these is a dramatic increase in the monitoring of antibiotic resistance, coupled with significant efforts to curb the indiscriminate use of antibiotics in order to extend their useful lifespan $[9,10]$. Efforts in this category include more stringent criteria before antibiotic prescription, more sensitive diagnostics before antibiotic use, increased emphasis on patient compliance (including use of full antibiotic

Key words: antibiotic, bacteriocin, targeted therapeutic, urinary tract infection (UTI). Abbreviations used: MIC, minimum inhibitory concentration; TMP-SMX, trimethoprim/ sulfamethoxazole; UTI, urinary tract infection; CAUTI, catheter-acquired UTI.

${ }^{1}$ To whom correspondence should be addressed (email riley@bio.umass.edu). courses), reduction and targeting of antibiotic use in food supplies (including animal feed and poultry processing), and an overall curb on the antibiotic load present in the environment [11-13].

Although efforts directed at educating physicians, patients and the general public have increased our awareness of the problem of antibiotic resistance and have, in some cases, resulted in a reduction in resistance rates, they do not obviate the need to develop new antibiotics. We stand at a critical juncture in this regard. One option is to continue to discover and develop new antibiotics as we have over the last halfcentury. That approach has involved the identification of compounds that exhibit high activity, broad range and low toxicity while meeting a variety of criteria involving stability and bioavailability. Within that framework, the prospect of antibiotic resistance is clearly seen as a major potential limitation on the utility and lifespan of any novel antibiotic, and the emergence of resistance treated as an unfortunate, undesirable, but unavoidable, cost of doing business with infectious agents.

\section{Bacteriocins as human therapeutics}

We contend that a second, more radical, approach to antibiotic development may be needed. Under this new paradigm, we acknowledge the lessons learned in the laboratory and in the clinic and incorporate the discoveries in genetics, genomics and microbial ecology into the search for and design of new antimicrobials. The goal of the present paper is to explore the potential for a large family of naturally occurring toxins to serve as a new generation of target-specific 'designer drugs' which are both effective against particular pathogens and reduce the emergence and spread of antibiotic resistance.

Our entry point into this new strategy is a family of highly evolved, highly toxic and highly specific antibiotic proteins: the bacteriocins. In terms of both abundance and diversity, bacteriocins contend for the prize as the primary mechanism 
of bacterial defence in Nature $[14,15]$. They are highly specific in their killing action, often active only against close relatives of the producing strains [15]. An ancient family of proteins, routinely employed by microbes to displace competitors and invade novel environments, they remain a viable highly effective means of bacterial defence. Why have bacteriocins retained their efficacy in an environment in which they are constantly in use? The answer is two-fold. First, because these toxins target a minute fraction of a microbial community, the selection for mutations that confer resistance is not taking place in multiple species simultaneously, as is the case with broad-spectrum antibiotics. Secondly, bacteriocins occur in constantly changing and evolving combinations, thus allowing the producer strains to keep pace with emergent resistance in the targets. It is precisely this strategy, i.e. targeted highly active antimicrobial agents supplied in changing combinations, that we emulate in our experimental therapeutic approach. We are convinced that this coupling will result in combinations that will be effective in vivo, exhibit virtually no toxicity to the host and greatly retard the emergence of resistance in the target pathogens. We argue that the natural ecology of antibiotics has much to teach us, not only about potential lead compounds, but also about the rational therapeutic use of antibiotics.

Why have we not already capitalized on this existing diversity of potential antimicrobials? The answer is simple. Until recently, physicians relied on symptom-based diagnosis and were thus often uncertain of the identity of the infecting agent(s). If the infection was bacteria-based, use of a broad-spectrum drug was almost always effective. Unfortunately, the overuse and abuse of these broadspectrum antibiotics has significantly reduced their efficacy [16]. The rapid development of molecular diagnostic methods now underway ushers in a different model for the treatment of infections, and frees us from our reliance on broad-spectrum antibiotics [17]. The time is right to assess the therapeutic potential of this highly diverse and abundant class of naturally occurring antimicrobials.

\section{The urinary tract infection model}

To illustrate the potential power of employing bacteriocins as an alternative for broad-spectrum antibiotics, we explore the efficacy and utility of their use in the treatment of UTIs (urinary tract infections), and, in particular, CAUTIs (catheter-acquired UTIs). These infections are widespread in the human population, with over 150 million people worldwide infected each year [18-20]. Women are especially prone to UTIs: more than one in five women develops a UTI during her lifetime, with many experiencing lifelong recurrences of urinary tract disease [21-24]. In addition, catheter-associated UTIs are the most common form of nosocomial infection in acute care hospitals and such infections are almost universally present among patients with chronic in-dwelling catheters, both in the community and in long-term care facilities [25]. Recent studies estimate that the cost of UTIs (including direct costs and indirect losses in
Figure 1 Inhibitory percentages of 96 uropathogenic $E$. coli strains for both traditional antibiotics (grey) and novel and known bacteriocins (black)

A standard bacteriocin assay was conducted using bacteriocin-producing strains tested against lawns of 96 uropathogenic E. coli. Inhibition was scored as a zone of cleaning surrounding the producer colony. Resistance profiles for the 96 uropathogenic E. coli were provided by Cooley Dickinson Hospital (Northampton, MA, U.S.A.). Any strains listed as sensitive to or inhibited by each antibiotic were scored as inhibition. Novel bacteriocins are labelled with Greek letters. Antibiotic abbreviations: am, ampicillin; sam, ampicillin/sulbactam; cip, ciprofloxacin; sxt, TMP-SMX; cz, cefazolin; fox, cefoxitin; ft, nitrofurantoin; gm, gentamicin.

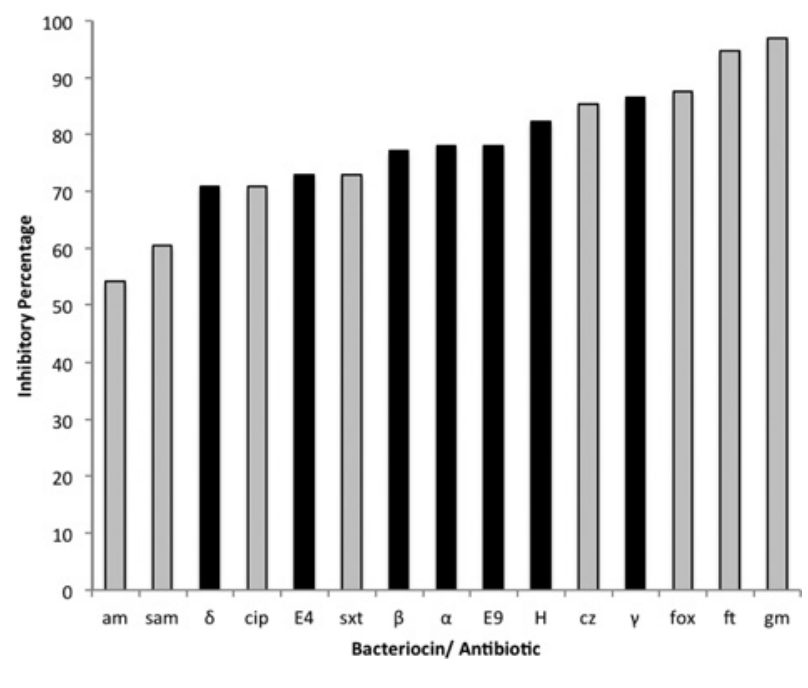

productivity due to illness or hospitalization) reaches US\$1.6 billion per year in the U.S.A. alone, excluding the costs of catheter-based infections [26].

Most UTIs are due to Escherichia coli, normally a commensal resident of the large intestine [27,28]. Other Gramnegative bacteria, including Klebsiella spp., Enterobacter spp., Serratia spp., Proteus mirabilis, Ps. aeruginosa and Enterococcus spp., are sometimes involved in UTIs [27,29,30]. $E$. coli is also the primary agent responsible for CAUTIs, with Ps. aeruginosa, Providencia stuartii and Staphylococci less frequently involved.

High levels of antibiotic resistance among the strains responsible for UTIs are creating a challenge to effective therapy [20,27,31-38]. Ampicillin and amoxicillin, formerly the cornerstones of UTI therapy, are no longer preferred because of high levels of resistance. TMP-SMX (trimethoprim/sulfamethoxazole) is considered the drug of choice for uncomplicated UTIs because of its low cost and wellestablished efficacy $[39,40]$. Levels of resistance to TMPSMX in E. coli now unfortunately range from $18 \%$ (for community-acquired infection) to $>30 \%$ (for hospitalacquired infection), suggesting that it will soon no longer be effective as a first-line therapeutic option [35,41,42]. Nitrofurantoin is also sometimes used in place of TMP-SMX or quinolones for treatment of UTIs. Aminoglycosides, the 
Figure 2 | In vivo effect of a bacteriocin applied to an established mouse UTI

Mice were treated with $2 \mu \mathrm{g}$ of a colicin bladder wash.

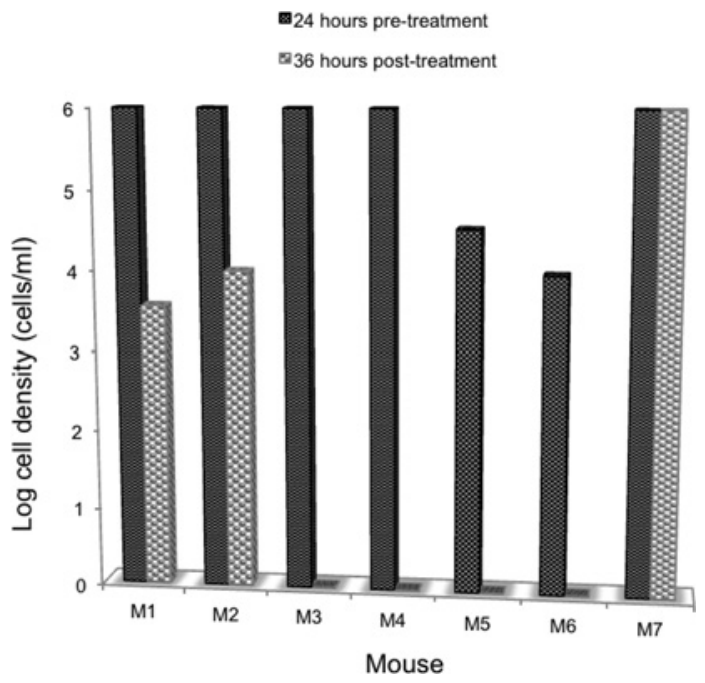

next line of defence, are highly effective for the treatment of infections caused by Gram-negative bacilli, including those strains causing UTIs. Their practical use, however, is limited due to high associated risk of nephro- and oro-toxicity. Fluoroquinolones also represent a significant advance in UTI therapy, but their cost and the importance of limiting their use, so as to prevent the emergence of resistant strains, excludes them as first-line therapy for uncomplicated UTIs, although they are the preferred drugs for complicated UTIs.

We have initiated investigations to explore the therapeutic potential of bacteriocins in the treatment of UTIs. Figure 1 shows the frequency of inhibition of 96 uropathogenic strains of $E$. coli with both classical antibiotics and novel and known bacteriocins. It is clear from these data that bacteriocins are as effective at inhibiting uropathogens as our most potent broad-spectrum drugs. Not shown are the data on MICs (minimum inhibitory concentrations) for these same drugs, which reveal that bacteriocins possess MICs as low as for the traditional antibiotics. One particularly vexing aspect of CAUTIs is that the uropathogens form dense biofilms on the catheter surfaces, which are virtually impossible to eliminate with classical antibiotics. In contrast, bacteriocins not only inhibit the growth of biofilms, but some even break down existing biofilms $[43,44]$.

Bacteriocins have been shown to be effective in vivo in several experimental systems. Figure 2 shows the in vivo effect of a bacteriocin applied to an established mouse UTI. A relatively small dose of bacteriocin $(\sim 2 \mu \mathrm{g})$ used as a bladder wash eliminated a well-established UTI in four of the seven mice tested, and significantly reduced uropathogen frequency in two additional mice. A further study revealed that simply coating a catheter with a bacteriocin-producing strain of bacteria before insertion eliminated subsequent biofilm formation [44].

The use of bacteriocins will ultimately select for resistant strains, just as is the case with classical antibiotics. However, because their therapeutic use would be directed at specific infections, the intensity of resistance selection would be dramatically decreased. Even more compelling, by combining two or three bacteriocins, a cocktail can be produced that reduces the resistance frequency by several orders of magnitude, significantly reducing the probability of the emergence of resistance as an outcome (Figure 3 ). Table 1 shows a second approach to combating resistance emergence: the use of a single bacteriocin with targeted substitutions that result in highly efficacious toxins with slightly altered specificity. The use of two or more of these variants results in a significantly reduced frequency of resistance.

Figure 3 | Colicin combinations reduce resistance frequency by several orders of magnitude

Crude lysates of colicins (equivalent units) were applied to a sensitive strain and resistance rates were measured

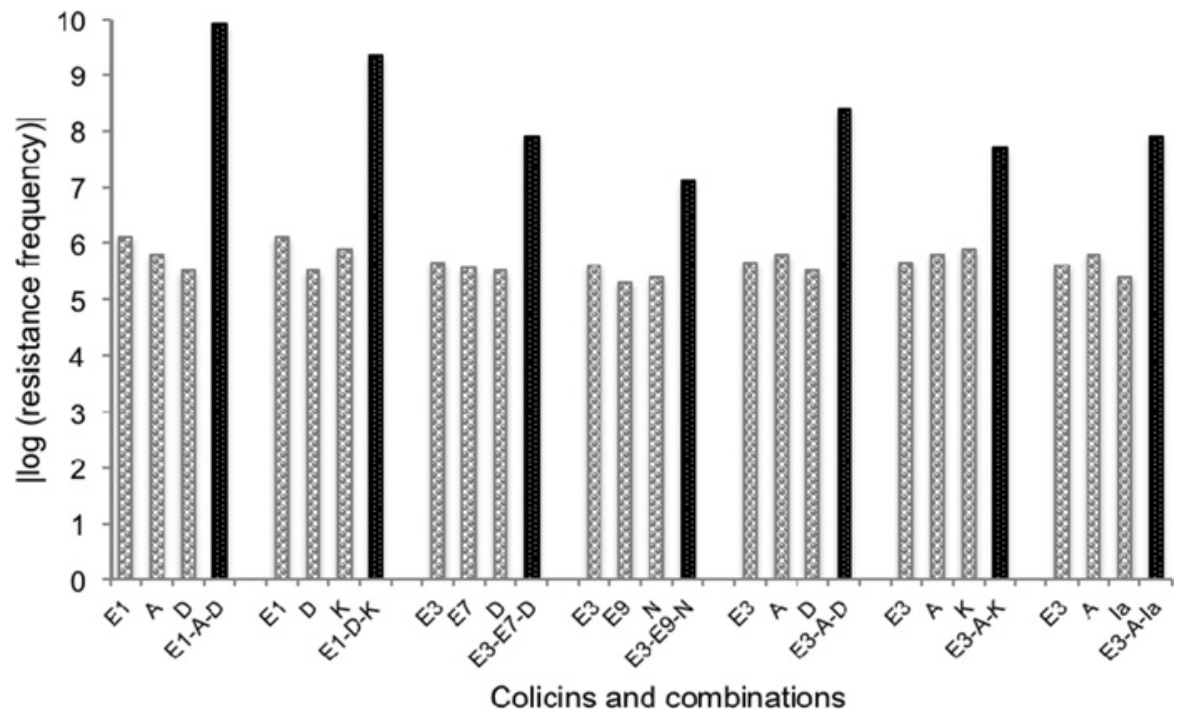


Table 1 Targeted substitutions in the receptor recognition region result in efficacious toxins with slightly altered receptor recognition specificity

\begin{tabular}{lll}
\hline Colicin variant & Mutation & Relative MIC \\
\hline E9.0 & None & 1.0 \\
E9.1 & L293R & 1.3 \\
E9.2 & L293H & 0.7 \\
E9.3 & R291H & 1.6 \\
E9.4 & R298H & 2.5 \\
\hline
\end{tabular}

\section{Conclusions}

In the present article, we can only begin to touch on the compelling features of bacteriocins that make them such an attractive candidate for therapeutic development. Some of these features include: targeted specificity, limited impact on normal healthy microflora of the patient, significant reduction in the selective pressures for resistance, a history of effective use in food preservation, mounting evidence of limited toxicity to mammalian cells, ease of production and their stable durable nature. There is much to be explored in the development of bacteriocins as therapeutic agents. However, all of the early signs suggest that this potent family of toxins can provide a compelling alternative approach to enable the production of an ecologically sound alternative for the treatment of infectious disease.

Antibiotic resistance is becoming a global health crisis, and there is no magic bullet on the horizon. The traditional paradigm for antibiotic discovery, development and therapy is not capable of responding to the rapid evolution and shifting ecology of our most virulent pathogens. We must act now to search for alternative solutions to this fundamental challenge to human health. We propose to develop a drug-development programme, based on sound ecological principles, which begins with lead compounds honed by three billion years of evolution. Our approach provides a bold challenge to the existing broad-spectrum drug discovery and development paradigm. If we are to outsmart germs at the game they play so well, we must attempt something radically different.

\section{Funding}

Supported by the National Institutes of Health [grant numbers R01 Al064588 and R01 GM068657], UMass Science and Technology Fund, UMass Life Science Moment Fund and Cooley Dickinson Hospital, Northampton, MA, U.S.A.

\section{References}

1 Bush, K., Courvalin, P., Dantas, G., Davies, J., Eisenstein, B., Huovinen, P., Jacoby, G.A., Kishony, R., Kreiswirth, B.N., Kutter, E. et al. (2011) Tackling antibiotic resistance. Nat. Rev. Microbiol. 9, 894-896

2 Levy, S.B. and Marshall, B. (2004) Antibacterial resistance worldwide: causes, challenges and responses. Nat. Med. 10, S122-S129

3 Livermore, D.M. (2003) Bacterial resistance: origins, epidemiology, and impact. Clin. Infect. Dis. 36, S11-S23
4 Pitout, J.D.D. and Laupland, K.B. (2008) Extended-spectrum $\beta$-lactamase-producing enterobacteriaceae: an emerging public-health concern. Lancet Infect. Dis. 8, 159-166

5 Arias, C.A. and Murray, B.E. (2009) Antibiotic-resistant bugs in the 21st century: a clinical super-challenge. N. Engl. J. Med. 360, 439-443

6 Fischbach, M.A. and Walsh, C.T. (2009) Antibiotics for emerging pathogens. Science 325, 1089-1093

7 Reference deleted

8 Roberts, R.R., Hota, B., Ahmad, I., Scott, R.D., Foster, S.D., Abbasi, F., Schabowski, S., Kampe, L.M., Ciavarella, G.G., Supino, M. et al. (2009) Hospital and societal costs of antimicrobial-resistant infections in a Chicago teaching hospital: implications for antibiotic stewardship. Clin. Infect. Dis. 49, 1175-1184

9 Mainous, III, A.G. and Pomeroy, C. (eds) (2010) Management of Antimicrobials in Infectious Diseases: Impact of Antibiotic Resistance, Humana Press, Totowa

10 Nugent, R., Back, E. and Beith, A. (2010) The Race Against Drug Resistance: a Report of the Center for Global Development's Drug Resistance Working Group, Center For Global Development, Washington, DC

11 Food and Drug Administration (2010) The Judicious Use of Medically Important Antimicrobial Drugs in Food-Producing Animals, Food and Drug Administration, Rockville

12 Andremont, A., Bonten, M., Kluytmans, J., Carmeli, Y., Cars, 0. and Harbarth, S. (2011) Fighting bacterial resistance at the root: need for adapted EMEA guidelines. Lancet Infect. Dis. 11, 6-8

13 Goff, D.A. (2011) Antimicrobial stewardship: bridging the gap between quality care and cost. Curr. Opin. Infect. Dis. 24 (Suppl. 1), S11-S20

14 Riley, M.A., Goldstone, C.M., Wertz, J.E. and Gordon, D. (2003) A phylogenetic approach to assessing the targets of microbial warfare. J. Evol. Biol. 16, 690-697

15 Riley, M.A. and Wertz, J.E. (2002) Bacteriocins: evolution, ecology, and application. Annu. Rev. Microbiol. 56, 117-137

16 Barbosa, T.M. and Levy, S.B. (2000) The impact of antibiotic use on resistance development and persistence. Drug Resist. Updates $\mathbf{3}$ 303-311

17 Zucca, M. and Savoia, D. (2010) The post-antibiotic era: promising developments in the therapy of infectious diseases. Int. J. Biomed. Sci. 6 , $77-86$

18 Yilmaz, N., Agus, N., Yurtsever, S.G., Pullukcu, H., Gulay, Z., Coskuner, A., Kose, S., Aydemir, S., Gulenc, N. and Ozgenc, O. (2009) Prevalence and antimicrobial susceptibility of Escherichio coli in outpatient urinary isolates in Izmir, Turkey. Med. Sci. Monit. 15, PI61-PI65

19 Harding, G.K. and Ronald, A.R. (1994) The management of urinary infections: what have we learned in the past decade? Int. J. Antimicrob. Agents 4, 83-88

20 Stamm, W.E. and Norrby, S.R. (2001) Urinary tract infections: disease panorama and challenges. J. Infect. Dis. 183 (Suppl. 1), S1-S4

21 Brumfitt, W. and Hamilton-Miller, J.M. (1998) Efficacy and safety profile of long-term nitrofurantoin in urinary infections: 18 years' experience. J. Antimicrob. Chemother. 42, 363-371

22 Foxman, B. (1990) Recurring urinary tract infection: incidence and risk factors. Am. J. Public Health $\mathbf{8 0}, 331-333$

23 Hooton, T.M. (2000) Pathogenesis of urinary tract infections: an update J. Antimicrob. Chemother. 46 (Suppl. A), 1-7

24 Hooton, T.M. and Stamm, W.E. (1997) Diagnosis and treatment of uncomplicated urinary tract infection. Infect. Dis. Clin. North Am. 11, 551-581

25 Warren, J.W. (1997) Catheter-associated urinary tract infections. Infect. Dis. Clin. North Am. 11, 609-622

26 Foxman, B. (2003) Epidemiology of urinary tract infections: incidence, morbidity, and economic costs. DM, Dis.-Mon. 49, 53-70

27 Kunin, C.M. (1997) Antibiotic armageddon. Clin. Infect. Dis. 25 , 240-241

28 Karlowsky, J.A., Hoban, D.J., Decorby, M.R., Laing, N.M. and Zhanel, G.G. (2006) Fluoroquinolone-resistant urinary isolates of Escherichio coli from outpatients are frequently multidrug resistant: results from the North American Urinary Tract Infection Collaborative Alliance-Quinolone Resistance study. Antimicrob. Agents Chemother. 50, 2251-2254

29 Hamilton-Miller, J.M. (1998) 'Think like a bacterium': a helpful concept to prolong the antibiotic era? Clin. Microbiol. Infect. 4, 177-178

30 Stickler, D.J. (2008) Bacterial biofilms in patients with indwelling urinary catheters. Nat. Clin. Pract. Urol. 5, 598-608

31 Felmingham, D. and Arakawa, S. (2001) Resistance among urinary tract pathogens: experience outside the USA. Clin. Drug Invest. 21, 7-11 
32 Gupta, K., Hooton, T.M. and Stamm, W.E. (2001) Increasing antimicrobial resistance and the management of uncomplicated community-acquired urinary tract infections. Ann. Int. Med. 135, 41-50

33 Kahlmeter, G. (2003) An international survey of the antimicrobial susceptibility of pathogens from uncomplicated urinary tract infections: the ECO.SENS Project. J. Antimicrob. Chemother. 51, 69-76

34 Karlowsky, J.A., Kelly, L.J., Thornsberry, C., Jones, M.E. and Sahm, D.F. (2002) Trends in antimicrobial resistance among urinary tract infection isolates of Escherichio coli from female outpatients in the united states. Antimicrob. Agents Chemother. 46, 2540-2545

35 Mazzulli, T. (2002) Resistance trends in urinary tract pathogens and impact on management. J. Urol. 168, 1720-1722

36 Murray, B.E., Alvarado, T., Kim, K.H., Vorachit, M., Jayanetra, P., Levine, M.M., Prenzel, I., Fling, M., Elwell, L., McCracken, G.H. et al. (1985) Increasing resistance to trimethoprim-sulfamethoxazole among isolates of Escherichio coli in developing countries. J. Infect. Dis. 152, 1107-1113

37 Seifert, R., Weinstein, D.M. and Li-McLeod, J. (2001) National prevalence of Escherichio coli resistance to trimethoprim-sulfamethoxazole: managed care implications in the treatment of urinary tract infections. J. Manag. Care Pharm. 7, 132

38 Talan, D.A., Stamm, W.E., Hooton, T.M., Moran, G.J., Burke, T., Iravani, A., Reuning-Scherer, J. and Church, D.A. (2000) Comparison of ciprofloxacin (7 days) and trimethoprim-sulfamethoxazole (14 days) for acute uncomplicated pyelonephritis pyelonephritis in women: a randomized trial. JAMA, J. Am. Med. Assoc. 283, 1583-1590
39 Miller, L.G. and Tang, A.W. (2004) Treatment of uncomplicated urinary tract infections in an era of increasing antimicrobial resistance. Mayo Clin. Proc. 79, 1048-1053

40 Nickel, J.C. (2005) Management of urinary tract infections: historical perspective and current strategies. Part 1. Before antibiotics. J. Urol. 173 21-26

41 Gupta, V., Yadav, A. and Joshi, R.M. (2002) Antibiotic resistance pattern in uropathogens. Indian J. Med. Microbiol. 20, 96-98

42 Raz, R., Chazan, B., Kennes, Y., Colodner, R., Rottensterich, E., Dan, M., Lavi, I. and Stamm, W. (2002) Empiric use of

trimethoprim-sulfamethoxazole (TMP-SMX) in the treatment of women with uncomplicated urinary tract infections, in a geographical area with a high prevalence of TMP-SMX-resistant uropathogens. Clin. Infect. Dis. 34, 1165-1169

43 Smith, K., Martin, L., Rinaldi, A., Rajendran, R., Ramage, G. and Walker, D. (2012) Activity of pyocin s2 against Pseudomonos aeruginosa biofilms. Antimicrob. Agents Chemother. 56, 1599-1601

44 Trautner, B.W., Hull, R.A. and Darouiche, R.0. (2005) Prevention of catheter-associated urinary tract infection. Curr. Opin. Infect. Dis. 18, $37-41$

Received 24 August 2012

doi:10.1042/BST20120179 